\title{
BMJ Open Open organisational culture: what does it entail? Healthcare stakeholders reaching consensus by means of a Delphi technique
}

\author{
Romana Fattimah Malik (D) , ${ }^{1}$ Martina Buljac-Samardžić, ${ }^{2}$ Insane Amajjar (D) , \\ Carina G J M Hilders, ${ }^{2}$ Fedde Scheele ${ }^{1,4}$
}

To cite: Malik RF, BuljacSamardžić M, Amajjar I, et al. Open organisational culture: what does it entail? Healthcare stakeholders reaching consensus by means of a Delphi technique. BMJ Open 2021;11:e045515. doi:10.1136/ bmjopen-2020-045515

- Prepublication history for this paper is available online. To view these files, please visit the journal online (http://dx.doi. org/10.1136/bmjopen-2020045515).

Received 06 0ctober 2020 Accepted 29 July 2021

D) Check for updates

C Author(s) (or their employer(s)) 2021. Re-use permitted under CC BY-NC. No commercial re-use. See rights and permissions. Published by BMJ.

${ }^{1}$ Research and Education, OLVG, Amsterdam, The Netherlands ${ }^{2}$ Health Policy and Management, Erasmus University Rotterdam, Rotterdam, The Netherlands ${ }^{3}$ Orthopaedic Surgery, OLVG, Amsterdam, The Netherlands ${ }^{4}$ Obstetrics and Gynaecology, Amsterdam University Medical Center, Amsterdam, The Netherlands

Correspondence to Dr Romana Fattimah Malik; romana_malik@hotmail.com

\section{ABSTRACT}

Objectives Open organisational culture in hospitals is important, yet it remains unclear what it entails other than its referral to 'open communication' in the context of patient safety. This study aims to identify the elements of an open hospital culture.

Methods In this group consensus study with a Delphi technique, statements were constructed based on the existing patient safety literature and input of 11 healthcare professionals from different backgrounds. A final framework consisting of 36 statements was reviewed on inclusion and exclusion, in multiple rounds by 32 experts and professionals working in healthcare. The feedback was analysed and shared with the panel after the group reached consensus on statements ( $>70 \%$ agreement).

Results The procedure resulted in 37 statements representing tangible (ie, leadership, organisational structures and processes, communication systems, employee attitudes, training and development, and patient orientation) and intangible themes (ie, psychological safety open communication, cohesion, power, blame and shame, morals and ethics, and support and trust). The culture themes' teamwork and commitment were not specific for an open culture, contradicting the patient safety literature. Thereby, an open mind was shown to be a novel characteristic.

Conclusions Open culture entails an open mind-set and attitude of professionals beyond the scope of patient safety in which there is mutual awareness of each other's (un)conscious biases, focus on team relationships and professional well-being and a transparent system with supervisors/leaders being role models and patients being involved. Although it is generally acknowledged that microlevel social processes necessary to enact patient safety deserve more attention, research has largely emphasised system-level structures and processes. This study provides practical enablers for addressing system and microlevel social processes to work towards an open culture in and across teams.

\section{INTRODUCTION}

Organisational culture (OC) in healthcare is often characterised as being 'unsafe' for healthcare professionals to speak-up and discuss errors, adverse events or
Strengths and limitations of this study

With this study, we have gained a better understanding of what an open culture in hospitals entails.

- This study provides a statement set that facilitate decision-makers with practical enablers on how leaders can be supportive in an open culture, how employees can contribute to an open culture and how healthcare organisations can work towards an open culture.

- The organisational culture concepts used are internationally recognised. Therefore, this study might be relevant to other contexts and settings.

- The main limitation is that data were collected from only one country; although this might limit the transferability of our findings, the results are likely generalisable to other countries with a similar health system.

- Another limitation is the use of a dichotomous scale in the questionnaire. To still allow for nuance in respondents' answers, respondents were given room in open questions to elaborate on their choices.

unprofessional behaviour of peers or supervisors. ${ }^{12}$ A survey of nearly 8000 doctors from the UK revealed that many doctors feel that they work in a dangerous and toxic environment with a blame culture that jeopardises patient safety and discourages learning and reflection. ${ }^{1}$ Healthcare organisations often fail to uncover concerns ${ }^{3}$ and face increasing pressure to enable professionals to critically reflect on and improve practices that negatively impact OC. Consequently, healthcare organisations are aiming for a so called 'open culture' (open OC) and emphasise its importance. ${ }^{4-18}$ research to date has not yet defined the elements of an open OC in healthcare.

In the past decades, OC research in healthcare was particularly conducted in the light of patient safety culture, especially since the report 'To err is human' by the Institute of Medicine in $1999 .{ }^{19}$ In this respect, various 
efforts have been made to stimulate a more open culture to ensure that patients receive safe and good quality care. ${ }^{8}$ Improvements regarding openness within patient safety cultures are mainly focused on communication around incidents. Within the patient safety literature, 'communication' covers structured communication processes (eg, reporting, hand-offs, time-outs and transparency about results) as well as the openness of communication in terms of speaking-up. ${ }^{20}$ Although communication is a key dimension in the majority of patient safety culture tools, ${ }^{21}$ its openness is still under-represented compared with the structured processes ${ }^{22}$ and speaking-up is difficult to address. ${ }^{23}$ At the same time, openness in communication has become an essential phenomenon in the light of an open OC. This brings us to the questions of how cultural dimensions related to openness relate to an open OC and whether 'open culture' is reflected by 'communication openness' or that it consists of an even bigger picture that goes beyond the traditional patient safety scope.

Although research on patient safety culture dominates the OC literature in healthcare and there is a clear description of its elements, it remains unclear which factors are components of an open OC that makes improving open OC a difficult path. Therefore, the aim of this study is to conceptualise what an open OC entails in healthcare by taking various stakeholders' perspectives into account. With this study, we expect to enhance current understanding, point the way for future research and enable effective strategies and solutions of future practices and education.

\section{METHODS}

\section{Setting and participants}

As the literature has proven to be inconclusive on what an open culture entails, a consensus study through a Delphi technique was considered to be the best approach to answer our research question. This study was conducted between September 2019 and March 2020 in the Netherlands. The Delphi technique allowed professionals working in healthcare to anonymously participate in this study, by assessing potential elements of open culture, online. The absence of group dynamics required careful consideration of individual input, but enabled sharing anonymised group feedback, in each round. We performed a modified Delphi technique, in which themes and statements were generated through literature and interviews; as opposed to a classical Delphi technique, in which themes and statements are generated by an expert panel. $^{24}$

A purposeful sampling approach was used in the selection of study participants as we aimed to research a variety of stakeholders. The included number of participants within a Delphi technique does not rely on power but on expertise and relevant knowledge. Studies using this technique typically have a panel of 10 to 20 participants. ${ }^{25-27}$ In line with this recommendation, we aimed at a panel of 12-18 experts combined with $12-18$ professionals working in practice to obtain diversity in stakeholders' views. ${ }^{28}$ Experts were defined as people with specific in-depth knowledge on OC, patient safety and communication openness in healthcare organisations. ${ }^{27}$ Professionals were defined as people who are a daily part of the OC, involved in patient safety, having first-hand experience of communication openness in hospital departments in specific, and therefore have a relevant say based on their experience and not based on specific knowledge on these subjects. The aim was to recruit OC experts in healthcare from different fields and professionals of different professional groups, such as surgical and non-surgical groups. Of the 19 experts that were invited, 18 participated and 1 declined, due to time constraints. All 14 professionals agreed to participate. This resulted in a panel of 32 participants (see table 1).

\section{Patient and public involvement}

Patients or the public were not involved in this study as this research focused solely on employees of the health setting.

\section{Delphi group consensus technique}

First, healthcare literature describing OC tools and their dimensions was used to develop a set of opinion statements. ${ }^{21}{ }^{29-43}$ The main researcher (RFM) developed a first set of 100 statements to represent different perspectives covering 16 OC themes in healthcare: 9 intangible themes (ie, commitment, trust, psychological safety, power, support, communication openness, blame and shame, morals and valuing ethics, and cohesion) and 7 tangible themes (ie, leadership, communication system, teamwork, training and development, organisational structures and processes, employee and job attributes, and patient orientation). ${ }^{21}$

The statements were initially based on the statements of three validated and most commonly used questionnaires to measure organisational culture in healthcare: Hospital Survey on Patient Safety Culture (HSOPSC), Safety Attitudes Questionnaire (SAQ) and Patient Safety Climate in Healthcare Organizations (PSCHO).$^{21}$ Subsequently, all statements were iteratively discussed by the research team across five meetings. As the majority of statements in these three questionnaires overlapped, the most appropriate wording of the statements was considered by the research team, and the remaining overlapping statements were removed. After the first meeting this resulted in nine statements of HSOPSC, nine statements of SAQ, four statements of PSCHO and one statement based on all three questionnaires. As these statements only covered part of the 16 OC themes, 9 statements on intangible themes were extracted from a literature review on OC. ${ }^{21}$ In the four other meetings, textual adjustments were made to statements that did not directly seem to fit the purpose of being an element for an open culture; this was aimed at not losing potential important themes or aspects of $\mathrm{OC}$ within these statements. The theme patient orientation was the only theme that could not be fully 
Table 1 Subject characteristics

\begin{tabular}{|c|c|c|c|c|c|}
\hline \multirow{2}{*}{$\begin{array}{l}\text { Subject characteristics } \\
\text { Professional background }\end{array}$} & \multirow[t]{2}{*}{$\mathrm{n}=32$} & \multicolumn{2}{|l|}{ Experts $(n=18)$} & \multicolumn{2}{|c|}{ Professionals $(n=14)$} \\
\hline & & $\begin{array}{l}\text { Healthcare inspectorate } \\
(n=3)\end{array}$ & & $\begin{array}{l}\text { Medical } \\
\text { specialists } \\
(\mathrm{n}=4)\end{array}$ & $\begin{array}{l}\text { Internal medicine, } \\
\text { paediatrics, obstetrics } \\
\text { and gynaecology, } \\
\text { orthopaedics }\end{array}$ \\
\hline & & $\begin{array}{l}\text { College of Medical } \\
\text { Specialisms }(n=3)\end{array}$ & & Nurses $(n=4)$ & $\begin{array}{l}\text { Acute care, intensive } \\
\text { care, orthopaedics, } \\
\text { surgery }\end{array}$ \\
\hline & & $\begin{array}{l}\text { Registration Committee for } \\
\text { Medical Specialists }(n=3)\end{array}$ & & $\begin{array}{l}\text { Residents } \\
(n=4)\end{array}$ & $\begin{array}{l}\text { Internal medicine, } \\
\text { neurology, obstetrics } \\
\text { and gynaecology, } \\
\text { cardiothoracic surgery }\end{array}$ \\
\hline & & Supervisory board $(n=1)$ & & $\begin{array}{l}\text { Hospital } \\
\text { management } \\
(n=2)\end{array}$ & $\begin{array}{l}\text { Plastic surgery, } \\
\text { obstetrics and } \\
\text { gynaecology }\end{array}$ \\
\hline & & Board of Directors $(n=2)$ & & & \\
\hline & & $\begin{array}{l}\text { Organisational culture } \\
\text { researchers }(n=3)\end{array}$ & & & \\
\hline & & $\begin{array}{l}\text { Human resource managers } \\
(\mathrm{n}=2)\end{array}$ & & & \\
\hline & & Hospital management $(n=1)$ & & & \\
\hline Male gender (\%) & $12(37.5)$ & $9(50)$ & & $3(21.4)$ & \\
\hline Age mean (SD) & $48.5(13.8)$ & $55.7(10.1)$ & range $30-69$ & $39.3(12.6)$ & range $25-66$ \\
\hline $\begin{array}{l}\text { Years of experience in } \\
\text { care mean (SD) }\end{array}$ & $20.3(12.7)$ & $25.9(10.7)$ & range $5-42$ & $13.1(11.5)$ & range $1-40$ \\
\hline $\begin{array}{l}\text { Years of experience with } \\
\text { organisational culture } \\
\text { mean (SD) }\end{array}$ & $11.0(11.6)$ & $18.7(10.6)$ & range $3-40$ & $3.7(7.1)$ & range $0-25$ \\
\hline
\end{tabular}

covered through (reformulating) statements of the three questionnaires. To cover this theme, the research team thought of two statements that could fit an open culture. This resulted in 34 remaining statements, of which only 11 were not modified as such so they could be traced back to the statements of the questionnaires.

Second, this set of 34 statements was pilot-tested in an individual interview setting by 11 professionals in the healthcare setting. The pilot focused on inclusion and exclusion, formulation and the need for adjustments or additional statements. The diversity in perspectives was ensured by including non-clinical as well as clinical participants with equal surgical and non-surgical backgrounds that is, a medical anthropologist, a medical educational advisor, two medical specialists, two residents, two nurses and three medical teachers. The pilot test resulted in various (textual) adjustments and two new statements; an element of open culture is one where (1) colleagues with prestige also show their vulnerabilities and (2) we approach each other positively, compliment each other and show appreciation. The final set consisted of 36 statements.

\section{Consensus and feedback}

The participants of this study were asked to review 36 statements on inclusion and exclusion in an online questionnaire. Additionally, they were asked whether they would like to make adjustments or add other statements. Substantially changed or new statements were presented for group consensus in each following round. As we used a dichotomous scale (inclusion or exclusion), consensus was expressed in percentages and was a priori, set on $70 \%$, which is in accordance with other studies that used a modified Delphi technique ${ }^{2444}$; once $70 \%$ of the expert panel had come to an agreement of the inclusion or exclusion of a statement, there was consensus. The anonymous responses were discussed and aggregated by the researchers, before they were shared with the participants in each round. After consensus was reached on a statement, participants were still given the opportunity to re-evaluate these statements in each following round to make adjustments and enhance validity. ${ }^{45}$ When there was a discrepancy in consensus between the experts and the professionals, the statement was reformulated with the help of the qualitative comments and presented in the following round. The results of each round were iteratively discussed by the research group and the Informed consent was obtained from all participants.

\section{Analysis}

The data were extracted anonymously and subsequently processed by the research team. The online questionnaire 


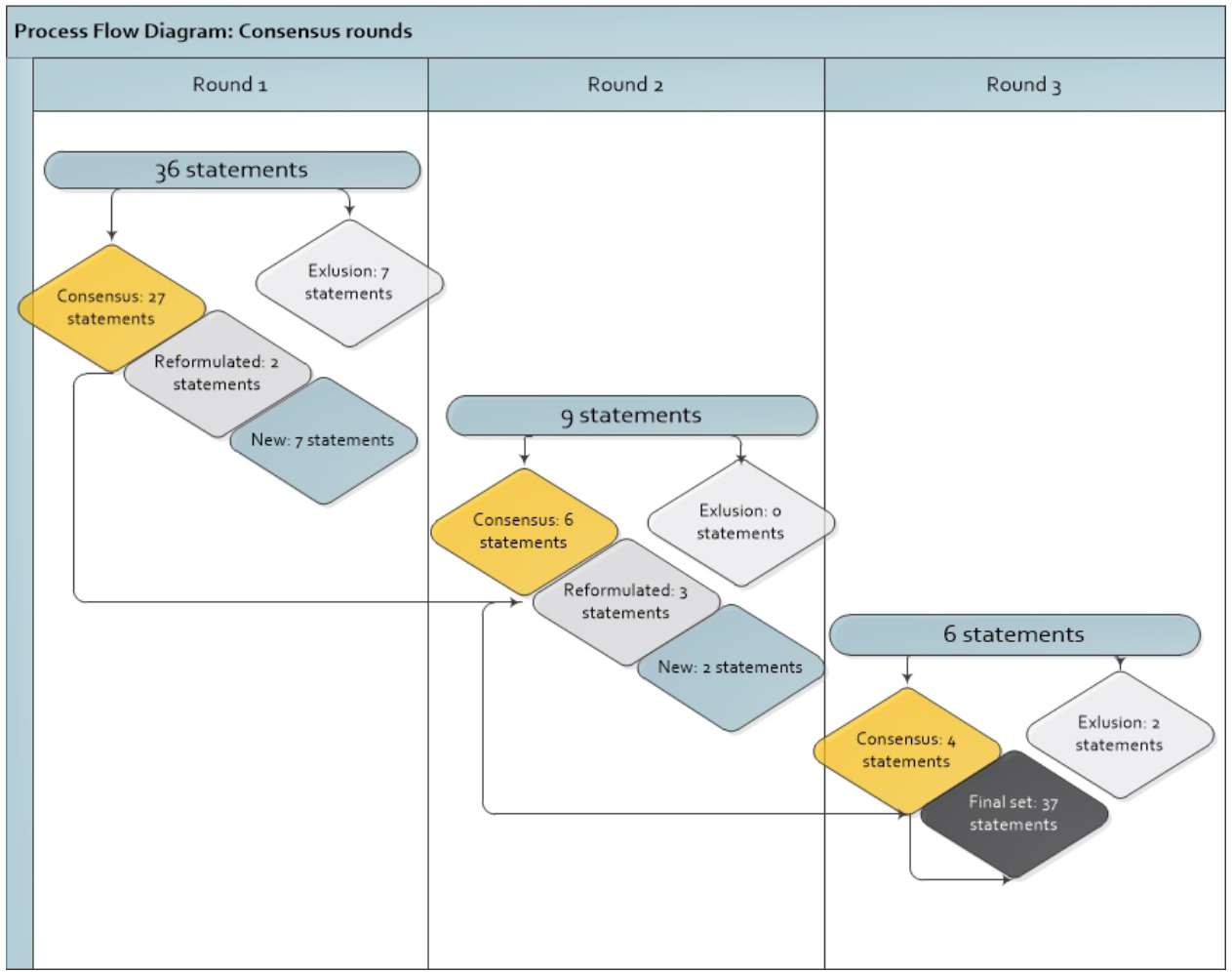

Figure 1 Process flow diagram of the Delphi procedure.

was developed with data management system Castor EDC. Microsoft Excel (2010) was used to respectively analyse the quantitative and qualitative data, and percentages were calculated from the distributions of answers. Qualitative comments were interpreted, discussed and processed by the research team. Quantitative and qualitative data of the experts and professionals were both analysed together and separately.

The final statement set was thematically coded with the tangible and intangible OC themes by the researchers. Each statement was categorised under two of these themes by a group consensus procedure among the researchers.

\section{RESULTS}

Three group consensus rounds were required to develop a final set (figure 1).

\section{Round 1}

In the first round of this Delphi technique, 32 panellists $(100 \%)$ evaluated 36 statements (table 1). Qualitative comments focused on textual shortcomings, redundancies and omissions. Consensus was reached on 27 of the 36 statements (table 2). Fourteen of these 27 statements were nuanced and/or textually adjusted, for example, words as maybe were deleted, without the content of the statement being changed. Seven of the nine statements with no consensus were excluded. Panellists commented that these seven statements that had aspects on the themes of teamwork and commitment, not specifically characteristic of an open culture; they argued that both themes could also be present in a culture that is not open. The following two statements were reformulated according to the feedback given in the qualitative comments since analysis showed a discrepancy in the consensus between the expert $(<70 \%)$ and professional group $(>70 \%)$ : (1) we work together as a team when a lot of work needs to be done quickly and (2) we pay sufficient attention to the use of each other's qualities in our daily routine. In addition, seven new statements were thought to be missing and were, together with the two reformulated statements, subject to evaluation in the second round of this Delphi technique (table 2). These new statements mainly focused on statements about communication openness, leadership being open about self-development and interprofessional collaboration.

\section{Round 2}

In the second round of this Delphi technique, 32 panellists $(100 \%)$ evaluated the total of nine statements. Six of the nine statements were included, of which five were subject to textual nuances and adjustments. The three statements on which no group consensus was reached were reformulated in response to the qualitative comments (table 2). The following two statements were reformulated because there was a discrepancy between the experts $(<70 \%$ consensus $)$ and the professionalgroup (>70\% consensus): (1) we are ready to help each other when work needs to be done and (2) managers are part of the team, professions and institutions. One statement was reformulated since panellists mentioned that this statement would be fit for inclusion if it did not focus on collaboration; that we work together in a broad 


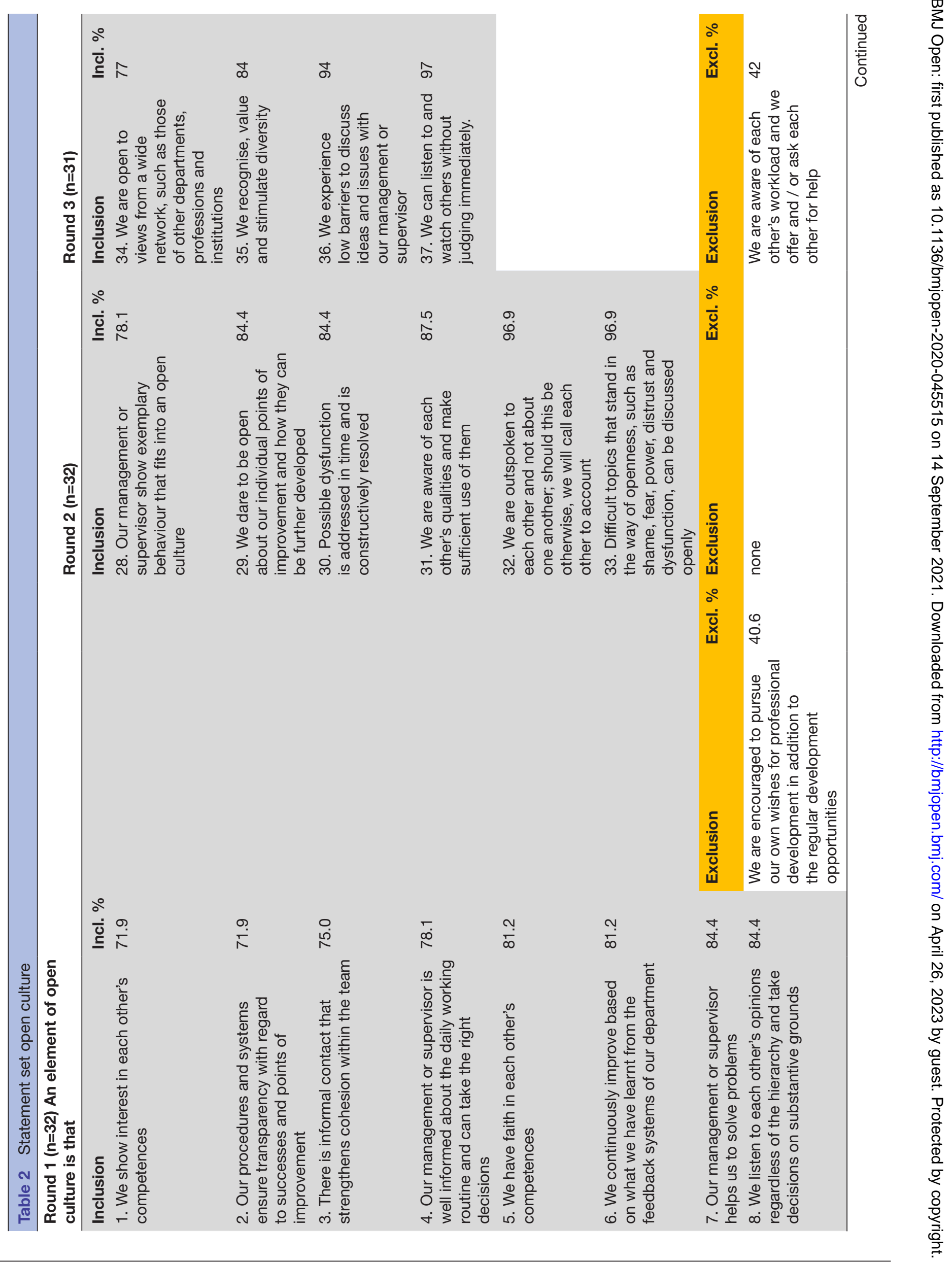




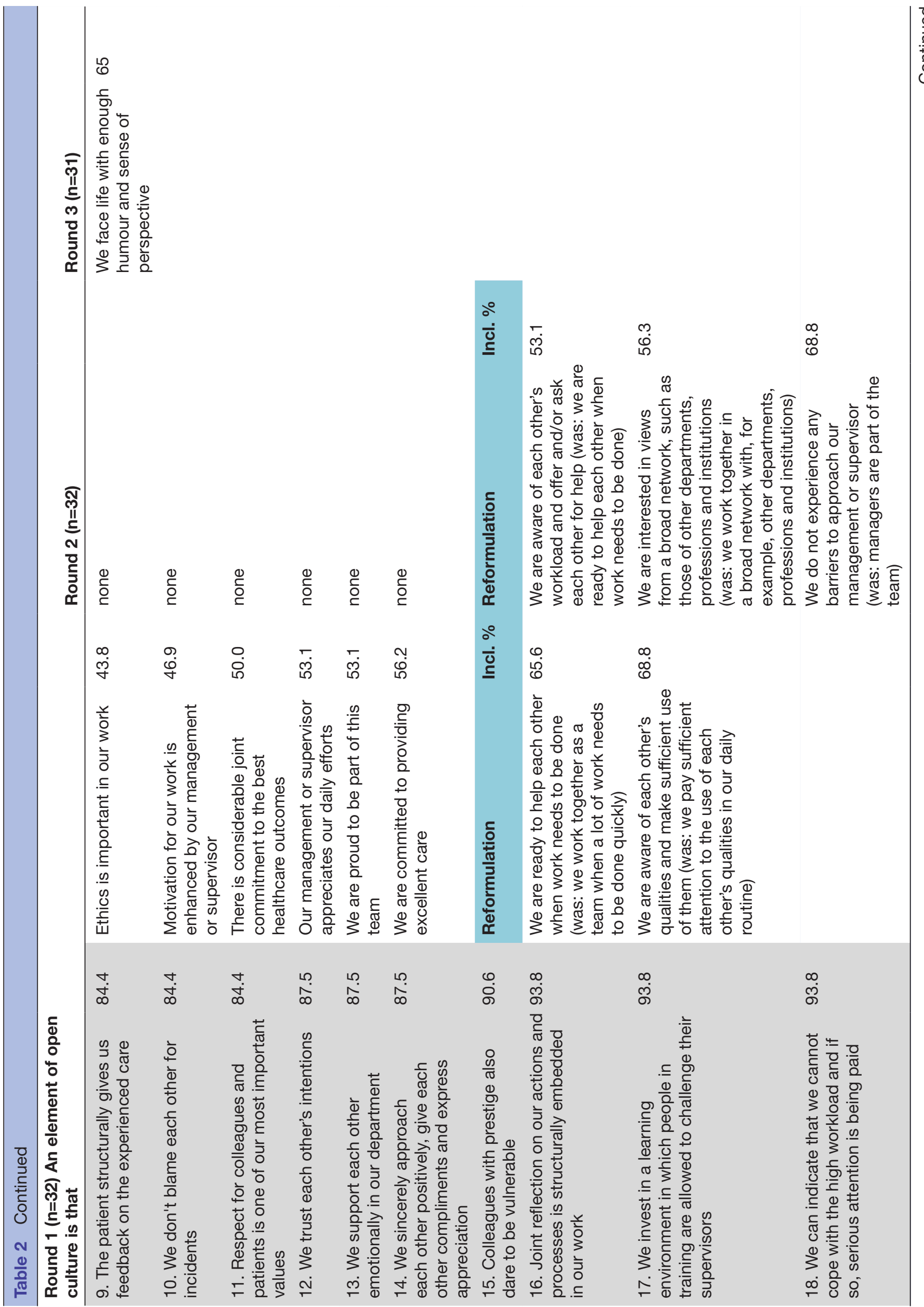




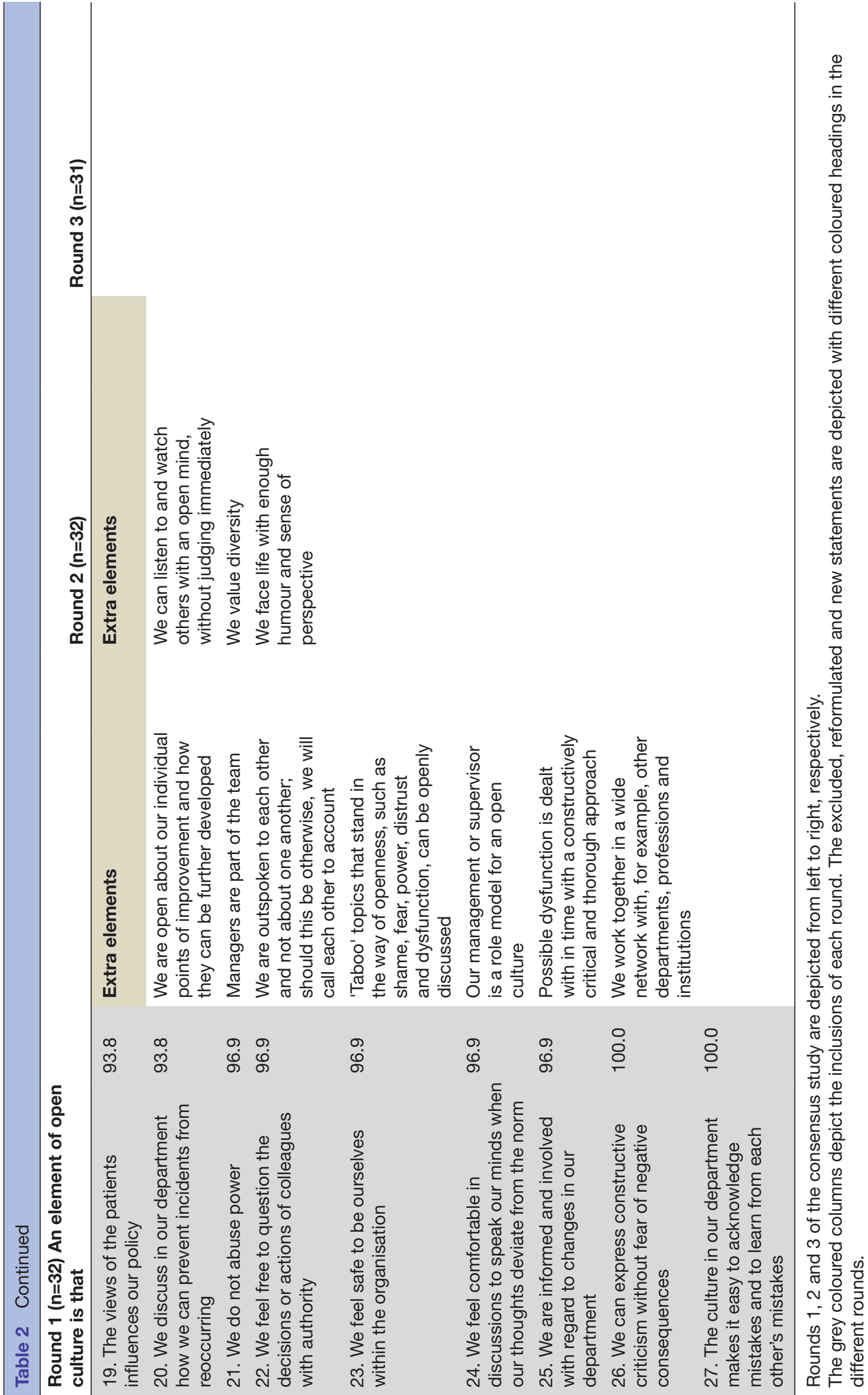


network with, for example, other departments, professions and institutions. In addition, three new statements were suggested by the participants in this round about not being judgemental, valuing diversity and facing life with enough humour. No adjustments were made to the included statements in round 1 , which resulted in a total of 33 included statements after the second round.

\section{Round 3}

In the last round of this Delphi technique, 31 panellists $(96.9 \%)$ reviewed a total of 6 statements (ie, 3 reformulated and 3 new) and included four of them. This resulted in a final set of 37 statements (table 2). The statements that were included were mostly about having an open mind to others and their perspectives. The statements that were excluded were as follows: (1) we are aware of each other's workload and we offer and/or ask each other for help and (2) we face life with enough humour and sense of perspective. The argument to exclude the first statement was similar to the arguments on teamwork in the first round.

\section{Thematic analysis of the final set}

Thematic analysis resulted in a connection graph (figure 2) showing how the identified 37 statements are related to themes and how these statements and themes are interrelated. Overall, there were more statements attached to intangible themes than to tangible themes.

Separately, themes covering the most statements were psychological safety, leadership, organisational structures and processes, communication openness, and employee and job attributes. The statements within the employee and job attributes theme were more focused on the subtheme employee attitude. Other themes that were found important, but were not represented by many statements, were cohesion, power, blame and shame, communication system, morals and ethics, support, trust, training and development, and patient orientation.

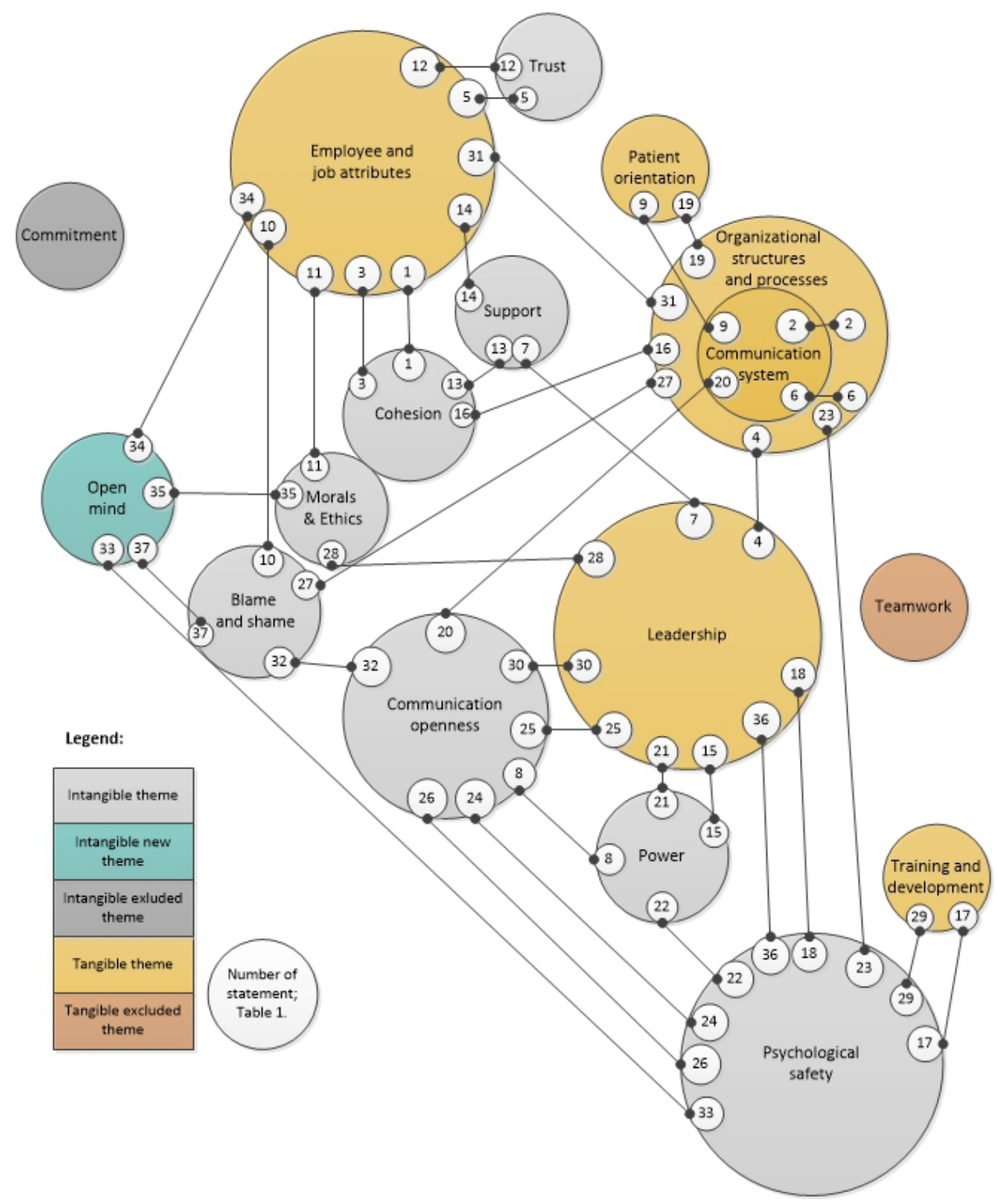

Figure 2 Connection graph of open culture elements and themes. 
One new intangible theme was developed: openmindedness; while two themes were deleted from the original theme set: commitment and teamwork. Although stakeholders found teamwork and commitment important themes, they argued that both could be present in a non-open culture and that it was not specific for the final set of themes of open culture.

\section{DISCUSSION}

This group consensus study conducted in the Netherlands, used a modified Delphi technique and identified 37 statements that together determine open OC within hospitals. The set of statements provides guidance to healthcare organisations that aim to work towards an open culture. An open culture is mostly characterised by intangible themes and less by tangible themes. It entails a culture in which there is continuous learning because employees (1) feel psychologically safe, (2) can communicate openly and (3) are open minded. In addition, an open culture is characterised by (4) transparent organisational structures and processes in which patients are involved, (5) employees who stimulate diversity, trust each other, approach each other positively, and have a positive attitude towards open communication and (6) supervisors/leaders who are supportive role models by not abusing power, not blaming and shaming, and maintaining high morals and ethics. Two themes that were considered as an important element of OC in the literature but were not found specifically contributing to an open culture were teamwork and commitment.

In recent years, evidence on the relationship between patient safety and healthcare worker safety culture continued to increase. ${ }^{46-48}$ In response, research has focused on related (sub)cultures or climates that take healthcare workers' psychological safety into account, such as just cultures, ${ }^{49}$ learning cultures ${ }^{50}$ and speaking-up cultures. ${ }^{51-53}$ These cultures are often related to subthemes of patient safety culture. A just culture, for example, has emerged as an imperative for improving the quality and safety of patient care. The concept is related to systems thinking in which incidents are approached as a systems and OC problem, rather than blaming individuals for it. It aims at creating an environment supportive of open dialogue to facilitate safer practice. ${ }^{49}{ }^{54}$ Other than in an open culture, the themes teamwork and commitment are specific for just and patient safety cultures. ${ }^{49} 54$

The National Health Service recently published a just culture guide with the aim to treat staff fairly and support a culture of fairness, openness and learning by making the staff feel confident to speak-up when things go wrong, rather than fearing blame. ${ }^{55}$ Kirkup $^{56}$ argues that the execution of this guide is lamentable. In their positive attempt to move from a blame culture to a just culture, it still remains unclear what a culture of openness entails and what attitude and mind-set is needed from healthcare professionals to get to that point.

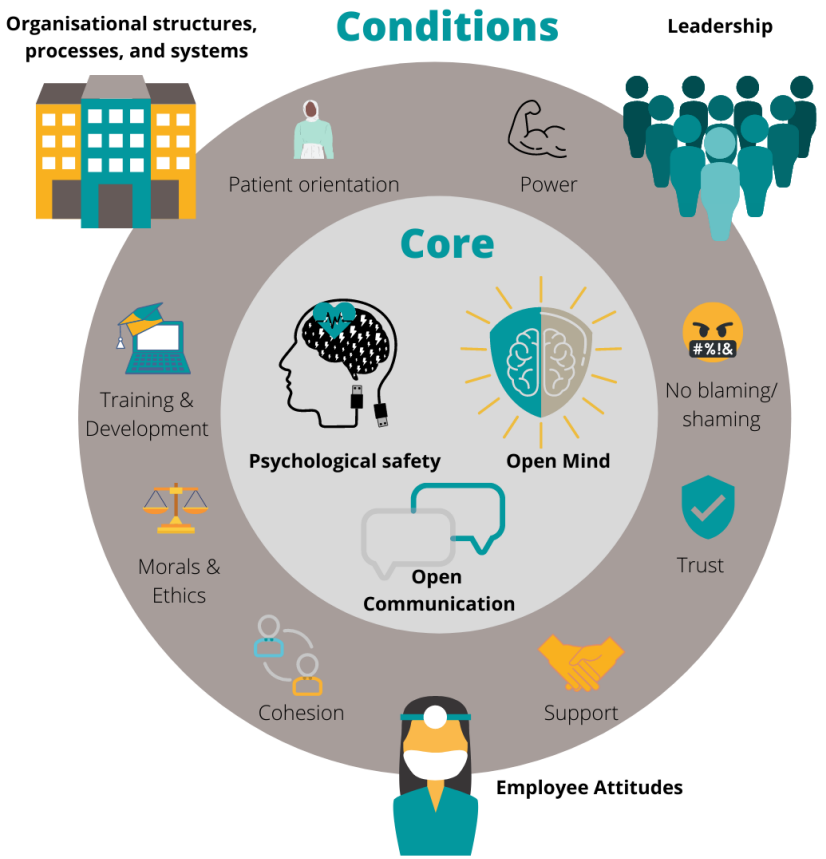

Figure 3 Core and conditions of open organisational culture.

Research on safety culture has been focussing mainly on the patient safety context while today's complex healthcare systems require increased focus on cultures that result in sustainable organisations, which includes retaining healthcare personnel. The current COVID-19 pandemic and its impact on the health workforce has again proven that this should be of utmost importance.

With exploring what open culture entails we have provided guidelines for social processes beyond the patient safety scope that need attention. This includes employees' thoughts, emotions, attitudes, safety and well-being, as well as the organisational conditions that need to be met. The major tangible themes of leadership, organisational structures and processes, and employee attitudes seem to form the conditional layer that need to be facilitated before the intangible core layer of values influencing psychosocial dynamics and relationships can exist (figure 3).

The tangible themes 'leadership' together with 'organisational structures and processes', and the intangible themes 'psychological safety' in addition to 'open communication' play an important role in open culture, just like in other OCs, and are already extensively discussed in the patient safety literature. An interesting result of this study however, is a clear focus on engaging patients as part of OC and an increased responsibility of employees for the way they behave and think; their attitude and mind-set eventually determine the openness of OC. In the following sections, we will address the themes patient orientation, employee attitude and open-mindedness. Moreover, we will introduce how the statement set can be used as a practical tool that facilitates dialogue.

First thing that was notable in our results is the patient orientation theme as derivative of organisational 
procedures. Although patients' interests are represented by patient councils in most hospitals on an executive level, daily practice policies still lack patient involvement in the middle and lower management. As policies on these levels involve direct patient care, we believe that working towards an open culture might be an advantage within the developments of patient involvement. Recent initiatives of involving patients in not only multidisciplinary meetings about their treatment plan, but also as partners in learning from unexpected events, and involvement in quality improvement and research already show positive results. ${ }^{57-59}$

Second, employee attitudes, one of the tangible preset conditions for open culture, was interesting. Open cultures are focused on the attitudes that employees take towards each other; it about showing interest, respecting, supporting, trusting, accepting and stimulating feedback and other perspectives, and approaching each other positively. Although employee attitudes reflect intrinsic human nature more than learnt behaviour, employees go through a process of professional socialisation in which they are socially constructed and largely shaped into conformity. ${ }^{60}$ In this process, they selectively acquire the values and attitudes, the interests, skills and knowledgein short, the culture-current in groups of which they are, or seek to become, a member. Attention should therefore be given to the role employees have in contributing to an open culture to generate a coherent pattern of employee behaviours that may encourage an open culture. A focus on self-critical analysis, human growth and development can contribute to and result in a shared understanding of assumptions, values and belief. Integrating concepts as interpersonal skills, an open attitude, an open mind-set and socialisation into medical education might positively shape professional identity and empower professionals in continuously improving the environment rather than getting moulded into a dysfunctional closed culture.

At last, an open mind is a new theme that was derived from our thematic analysis and is very much related to being aware of (un) conscious biases and its resulting attitudes. Open mind entails that the team recognises, values and stimulates diversity; that they are open to perspectives from a wide network by listening and watching others without judging immediately, and by discussing difficult topics that stand in the way of openness, such as shame, fear, power, distrust and dysfunction. Mitchell and Boyle ${ }^{61}$ combined different perspectives on openmindedness and described it as collective views on how members should respond to the divergent ideas and opinions of other members, a willingness to examine and challenge assumptions, and the perception that all members should be able to voice their different views without restriction. Open-mindedness as a concept can be related to the concept of 'critical thinking' in the context of education and stimulating creativity. In 1910, Dewey ${ }^{62}$ defined critical thinking as 'reflective thought', that is, to suspend judgement, maintain a healthy scepticism, and exercise an open mind; Dewey's definition suggests that critical thinking has both an intellectual and an emotional component. It refers to characteristics of the individual, personality traits or habits of the mind. Although openmindedness is researched in the context of learning, there is little research about open-mindedness in the light of patient safety culture. Long et $a l^{63}$ found that open-mindedness is one of the least important and least trainable skills that contributes to patient safety. However, Royce et $a l^{64}$ argue that explicit instruction in metacognition in medical education, including awareness of cognitive biases, has the potential to reduce diagnostic errors and thus improve patient safety. Other research showed that open-minded healthcare professionals are necessary in the context of healthcare innovation. ${ }^{61}$ Just as the competence of open communication, we believe that open-mindedness deserves attention within healthcare professional education. Attention should specifically be given to group maturity; the more the group has shared emotionally intensive experiences, the stronger the culture of that group will be to inevitably reinforce its assumptions about itself and its environment. ${ }^{65}$ Creativity and member differences are therefore seen as threat and the group may lose the ability to adapt, innovate and grow. In addition, we should focus on the stereotyping mentality that healthcare professionals develop when they gain expertise. ${ }^{66}$ Shortcuts in our ways of seeing and understanding the world can be extremely powerful and pleasing ways of categorising and dealing with new situations by treating them like the things that we have encountered before (yet, wrongly over generalised, these become the raw ingredient of prejudice and bigotry). ${ }^{66}$ Rushmer and Davies ${ }^{66}$ argue that open-mindedness is a vital ingredient of successful unlearning of these mental shortcuts.

\section{A practical tool to facilitate dialogue}

The statement set in table 2 in conjunction with the themes in figure 2 has been considered as a useful tool in practice to facilitate dialogue and help decision-makers to focus on the social processes next to the system level. However, further research is required to evaluate the list of statements, and how it could be developed into a valid and reliable tool.

\section{LIMITATIONS}

The main limitation is that data were collected from only one country. Although this might limit the transferability of our findings, the results are likely generalisable to other countries with a similar health system. Also, we think we can justify the assumption that our findings will have some relevance and potential transferability to other contexts and settings since the OC concepts used are internationally recognised. Another limitation is the use of a dichotomous scale in the questionnaire. To still allow for nuance in respondents' answers, respondents were given room in open questions to elaborate on their choices. 


\section{CONCLUSION}

With this study, we have gained a better understanding about what an open culture in hospitals entails from a stakeholder's perspective, and how it relates to patient safety culture and other similar concepts. An open culture encompasses much more than 'open communication' in the context of patient safety. Open culture refers to transparency and openness on system and microlevel. Open culture entails social processes in broad daylight beyond the culture literature, such as patient safety culture, by including an open attitude and open mind-set of employees and leaders, as well as other organisational conditions that need to be met. The statement set facilitates healthcare organisations to address these social processes beyond the patient safety context and work towards an open culture.

Contributors All authors made substantial contributions to the conception and design of the work; the acquisition, analysis and interpretation of data for the work. RFM, MB-S, IA and FS drafted the manuscript and RFM, MB-S, IA, CGJMH and FS revised the manuscript critically for important intellectual content. All authors gave final approval of the version to be published and agree to be accountable for all aspects of the work in ensuring that questions related to the accuracy or integrity of any part of the work are appropriately investigated and resolved.

Funding The authors have not declared a specific grant for this research from any funding agency in the public, commercial or not-for-profit sectors.

\section{Competing interests None declared.}

Patient and public involvement Patients and/or the public were not involved in the design, or conduct, or reporting, or dissemination plans of this research.

\section{Patient consent for publication Not required.}

Ethics approval The study was approved by the ethical review committee of OLVG hospital (file number W016.623).

Provenance and peer review Not commissioned; externally peer reviewed.

Data availability statement Data are available upon reasonable request. Data on the development of the first statement set and the consensus procedure can be made available by request to the corresponding author.

Open access This is an open access article distributed in accordance with the Creative Commons Attribution Non Commercial (CC BY-NC 4.0) license, which permits others to distribute, remix, adapt, build upon this work non-commercially, and license their derivative works on different terms, provided the original work is properly cited, appropriate credit is given, any changes made indicated, and the use is non-commercial. See: http://creativecommons.org/licenses/by-nc/4.0/.

\section{ORCID iDs}

Romana Fattimah Malik http://orcid.org/0000-0001-8061-9791

Ihsane Amajjar http://orcid.org/0000-0001-5464-8636

\section{REFERENCES}

1 Wise J. Survey of UK doctors highlights blame culture within the NHS. BMJ 2018;362:k4001.

2 Voogt JJ, Kars MC, van Rensen ELJ, et al. Why medical residents do (and don't) speak up about organizational barriers and opportunities to improve the quality of care. Acad Med 2020;95:574-81.

3 Martin GP, Aveling E-L, Campbell A, et al. Making soft intelligence hard: a multi-site qualitative study of challenges relating to voice about safety concerns. BMJ Qual Saf 2018;27:710-7.

4 Elcock K. Raising concerns in an open culture. Br J Nurs 2013;22:1140.

5 Morrow KJ, Gustavson AM, Jones J. Speaking up behaviours (safety voices) of healthcare workers: a metasynthesis of qualitative research studies. Int J Nurs Stud 2016;64:42-51.

6 Shaw R. Patient safety: the need for an open and fair culture. Clin Med 2004;4:128-31.
7 Zwijnenberg NC, Hendriks M, Hoogervorst-Schilp J, et al. Healthcare professionals views on feedback of a patient safety culture assessment. BMC Health Serv Res 2016;16:199.

8 Wagner $\mathrm{C}$, Smits M, Sorra J, et al. Assessing patient safety culture in hospitals across countries. Int J Qual Health Care 2013;25:213-21.

9 Donaghy C, Doherty R, Irwin T. Patient safety: a culture of openness and supporting staff. Surgery 2018;36:509-14.

10 Toffolutti V, Stuckler D. A culture of openness is associated with lower mortality rates among 137 English National health service acute trusts. Health Aff 2019;38:844-50.

11 Crowe S, Clarke N, Brugha R. 'You do not cross them': hierarchy and emotion in doctors' narratives of power relations in specialist training. Soc Sci Med 2017;186:70-7.

12 Bynum WE, Lindeman B. Caught in the middle: a resident perspective on influences from the learning environment that perpetuate mistreatment. Acad Med 2016;91:301-4.

13 Mannion R, Davies H. Raising and responding to frontline concerns in healthcare. BMJ 2019;366:14944.

14 Tomlinson R. East Lancashire Hospital Trust creates an open culture paving the way for service improvement 'Below ten thousand'. $J$ Perioper Pract 2018;28:115-9.

15 Ravaghi H, Mannion R, Sajadi HS. Organizational failure in an NHS Hospital trust: a qualitative study. Health Care Manag 2015;34:367-75

16 Bank L, Jippes M, van Rossum TR, et al. How clinical teaching teams deal with educational change: 'we just do it'. BMC Med Educ 2019;19:377.

17 Birks Y, Harrison R, Bosanquet K. An exploration of the implementation of open disclosure of adverse events in the UK: a scoping review and qualitative exploration. Health Serv Deliv Res 2014.

18 Martin GP, Chew S, Dixon-Woods M. Senior stakeholder views on policies to foster a culture of openness in the English National Health Service: a qualitative interview study. J R Soc Med 2019;112:153-9.

19 Kohn LT, Corrigan JM, Donaldson MS. To err is human: building a safer health system. Washington, DC: National Academies Press, 2000.

20 Sammer CE, Lykens K, Singh KP, et al. What is patient safety culture? A review of the literature. J Nurs Scholarsh 2010;42:156-65.

21 Malik RF, Buljac-Samardžić M, Akdemir N, et al. What do we really assess with organisational culture tools in healthcare? an interpretive systematic umbrella review of tools in healthcare. BMJ Open Qual 2020;9:e000826.

22 Martinez W, Etchegaray JM, Thomas EJ, et al. 'Speaking up' about patient safety concerns and unprofessional behaviour among residents: validation of two scales. BMJ Qual Saf 2015;24:671-80.

23 Dixon-Woods M, Campbell A, Martin G, et al. Improving employee voice about transgressive or disruptive behavior: a case study. Acad Med 2019;94:579-85.

24 Keeney S, Hasson F, McKenna HP. The Delphi technique in nursing and health research. Chichester, West Sussex: Wiley-Blackwell, 2011.

25 McPherson S, Reese C, Wendler MC. Methodology update: Delphi studies. Nurs Res 2018:67:404-10.

26 Ludwig B. Predicting the future: have you considered using the Delphi methodology. J Extension 1997;35:1-4.

27 Wanda LS-G, Tena BC. The Delphi technique: a research strategy for career and technical education. J Career Tech Educ 2004;20.

28 Hussler C, Muller P, Rondé P. Is diversity in Delphi panelist groups useful? Evidence from a French forecasting exercise on the future of nuclear energy. Technol Forecast Soc Change 2011;78:1642-53.

29 Scott $\mathrm{T}$, Mannion R, Davies $\mathrm{H}$, et al. The quantitative measurement of organizational culture in health care: a review of the available instruments. Health Serv Res 2003;38:923-45.

30 Gershon RRM, Stone PW, Bakken S, et al. Measurement of organizational culture and climate in healthcare. J Nurs Adm 2004;34:33-40.

31 Colla JB, Bracken AC, Kinney LM, et al. Measuring patient safety climate: a review of surveys. Qual Saf Health Care 2005;14:364-6.

32 King T, Byers JF. A review of organizational culture instruments for nurse executives. J Nurs Adm 2007;37:21-31.

33 Jung T, Scott T, Davies HTO, et al. Instruments for exploring organizational culture: a review of the literature. Public Adm Rev 2009;69:1087-96.

34 Freeth D, Sandall J, Allan T, et al. A methodological study to compare survey-based and observation-based evaluations of organisational and safety cultures and then compare both approaches with markers of the quality of care. Health Technol Assess 2012;16:iii-184.

35 Pumar-Méndez MJ, Attree M, Wakefield A. Methodological aspects in the assessment of safety culture in the hospital setting: a review of the literature. Nurse Educ Today 2014;34:162-70. 
36 Manser T, Brösterhaus M, Hammer A. You can't improve what you don't measure: Safety climate measures available in the Germanspeaking countries to support safety culture development in healthcare. Z Evid Fortbild Qual Gesundhwes 2016;114:58-71.

37 Chaneliere M, Jacquet F, Occelli P, et al. Assessment of patient safety culture: what tools for medical students? BMC Med Educ 2016;16:255.

38 Flin R, Burns C, Mearns K, et al. Measuring safety climate in health care. Qual Saf Health Care 2006;15:109-15.

39 Mannion R, Konteh FH, Davies HTO. Assessing organisational culture for quality and safety improvement: a national survey of tools and tool use. Qual Saf Health Care 2009;18:153-6.

40 Halligan M, Zecevic A. Safety culture in healthcare: a review of concepts, dimensions, measures and progress. BMJ Qual Saf 2011;20:338-43.

41 Alsalem G, Bowie P, Morrison J. Assessing safety climate in acute hospital settings: a systematic review of the adequacy of the psychometric properties of survey measurement tools. BMC Health Serv Res 2018;18:353.

42 Lawati MHA, Dennis S, Short SD, et al. Patient safety and safety culture in primary health care: a systematic review. BMC Fam Pract 2018;19:104.

43 Palmieri P, Peterson L, Pesta B. Safety culture as a contemporary healthcare construct: theoretical review, research assessment, and translation to human resource management. Adv Health Care Manage 2010;9:97-133.

44 de Villiers MR, de Villiers PJT, Kent AP. The Delphi technique in health sciences education research. Med Teach 2005;27:639-43.

45 Hasson F, Keeney S, McKenna H. Research guidelines for the Delphi survey technique. J Adv Nurs 2000;32:1008-15

46 Yassi A, Hancock T. Patient safety-worker safety: building a culture of safety to improve healthcare worker and patient well-being. Healthc Q 2005;8:8.

47 Eklöf M, Törner M, Pousette A. Organizational and socialpsychological conditions in healthcare and their importance for patient and staff safety. A critical incident study among doctors and nurses. Saf Sci 2014;70:211-21.

48 Daugherty Biddison EL, Paine L, Murakami P, et al. Associations between safety culture and employee engagement over time: a retrospective analysis. BMJ Qual Saf 2016;25:31-7.

49 Khatri N, Brown GD, Hicks LL. From a blame culture to a just culture in health care. Health Care Manage Rev 2009;34:312-22.

50 Bynum WE, Haque TM. Risky business: psychological safety and the risks of learning medicine. J Grad Med Educ 2016;8:780-2.
51 Ginsburg L. 'Speaking up' climate: a new domain of culture to measure and explore. BMJ Qual Saf 2015;24:661-3.

$52 \mathrm{Ng}$ GWY, Pun JKH, So EHK, et al. Speak-up culture in an intensive care unit in Hong Kong: a cross-sectional survey exploring the communication openness perceptions of Chinese doctors and nurses. BMJ Open 2017;7:e015721.

53 Schwappach D, Sendlhofer G, Häsler L, et al. Speaking up behaviors and safety climate in an Austrian university hospital. Int J Qual Health Care 2018;30:701-7.

54 Waterson P. Patient safety culture: theory, methods and application, 2018.

55 NHS. A just culture guide United Kingdom NHS 2018, 2018. Available: https://improvement.nhs.uk/resources/just-cultureguide/

56 Kirkup B. Nhs improvement's just culture guide: good intentions failed by flawed design. J R Soc Med 2019;112:495-7.

57 Rosell L, Alexandersson N, Hagberg O, et al. Benefits, barriers and opinions on multidisciplinary team meetings: a survey in Swedish cancer care. BMC Health Serv Res 2018;18:249.

58 Etchegaray JM, Ottosen MJ, Aigbe A, et al. Patients as partners in learning from unexpected events. Health Serv Res 2016;51 Suppl 3:2600-14

59 Harrington RL, Hanna ML, Oehrlein EM, et al. Defining patient engagement in research: results of a systematic review and analysis: report of the ISPOR patient-centered special interest group. Value Health 2020;23:677-88.

60 Clouder L. Becoming professional: exploring the complexities of professional socialization in health and social care. Learn Health Social Care 2003;2:213-22.

61 Mitchell R, Boyle B, diversity P. Professional diversity, identity salience and team innovation: the moderating role of openmindedness norms. J Organ Behav 2015;36:873-94.

62 Dewey J. How we think. [Place of publication not identified]. Nabu Press, 2010.

63 Long S, Arora S, Moorthy K, et al. Qualities and attributes of a safe practitioner: identification of safety skills in healthcare. BMJ Qual Saf 2011:20:483-90.

64 Royce CS, Hayes MM, Schwartzstein RM. Teaching critical thinking: a case for instruction in cognitive biases to reduce diagnostic errors and improve patient safety. Acad Med 2019;94:187-94.

65 Schein EH, Ebooks C. Organizational culture and leadership. San Francisco: Jossey-Bass, 2010.

66 Rushmer R, Davies HTO. Unlearning in health care. Qual Saf Health Care 2004;13:ii10-15. 